\title{
Exclusive breastfeeding among women with type 1 and type 2 diabetes mellitus
}

\author{
Leandro Cordero ${ }^{*}$, Michael R. Stenger ${ }^{1}$, Mark B. Landon ${ }^{2}$ and Craig A. Nankervis ${ }^{1}$
}

\begin{abstract}
Objective: To compare exclusive breastfeeding (BF) and BF initiation among 185 women with Type 1 and 212 women with Type 2 pregestational diabetes who intended exclusive or partial BF and delivered at $\geq 34$ weeks of gestation.

Methods: Retrospective cohort study. At discharge, exclusive BF is direct BF or BF complemented with expressed breast milk. BF initiation is defined by exclusive or partial BF.

Results: Type 1 and Type 2 groups were similar in prior BF experience (69 vs 67\%) but were different in intention to BF exclusively (92 vs 78\%) and partially (8 vs 22\%). Women in the Type 1 group were younger (median age 30 vs 33y), likely to be primiparous (47 vs 25\%), have a lower median BMI (32 vs $36 \mathrm{~kg} / \mathrm{m}^{2}$ ) and deliver by primary cesarean (37 vs 26\%). Infants born to Type 1 women were more likely to be admitted to the NICU (44 vs 18\%) and to have hypoglycemia (59 vs 41\%). At discharge, exclusive BF among Type 1 was higher (34 vs 23\%), partial BF was similar (47 vs 46\%) while FF (formula feeding) was lower (19 vs 31\%) than in the Type 2 group. BF initiation occurred in 81\% of Type 1 and $69 \%$ of Type 2 women.
\end{abstract}

Conclusion: Intention to BF exclusively was higher in Type 1 women compared to Type 2. At discharge, exclusive BF and BF initiation were lower and FF higher in the Type 2 group highlighting the need for different strategies if lactation in this special population is to be improved.

Keywords: Exclusive breastfeeding and type 1 and type 2 diabetes mellitus

\section{Background}

Pregestational diabetes mellitus (Type 1 and Type 2) affects $1-1.5 \%$ of all pregnant women and may lead to adverse maternal and neonatal outcomes [1]. Other investigators noted an increase in pregestational diabetes as well as preeclampsia, chronic hypertension and obesity among women hospitalized for delivery in the US from 2005 through 2014 [2]. Additionally, investigators in California observed an alarming rise in the prevalence of Type 1 and Type 2 diabetes as well as racial/ethnic

\footnotetext{
*Correspondence: Leandro.cordero@osumc.edu

1 Department of Pediatrics, College of Medicine, The Ohio State University Wexner Medical Center, N118 Doan Hall, 410 W. 10th Avenue, Columbus, $\mathrm{OH}$ 43210-1228, USA

Full list of author information is available at the end of the article
}

disparities in pregnant women from 1996 through 2014 [3]. Of the patients studied, $24 \%$ were classified as Type 1 and $76 \%$ as Type 2 . Women in the Type 2 group tended to be older, African American or Hispanic, multiparous, had a high BMI and delivered by cesarean [3].

Earlier publications on breastfeeding (BF) focused mainly on women with Type 1 or reported small samples of Type 1 and Type $2[4,5]$. A collaborative study confirmed that the duration of exclusive and overall BF was shorter in Type 1 than in non-diabetic women [6]. More recently, Herskin et al. compared 105 Type 1 with 44 Type 2 dyads and reported different BF rates at hospital discharge (76 vs $45 \%)$ and at 4 months postpartum ( 49 vs 23\%) [7].

Lactation is critical because it provides short- and long-term health benefits to mothers and their infants 
following healthy pregnancies as well as those compromised by gestational and pregestational diabetes [8-11]. Despite the above, comparisons of exclusive BF and BF initiation rates among women with Type 1 and Type 2 diabetes remain scarce and deserves further study.

\section{Objective}

To compare exclusive BF and BF initiation among 185 women with Type 1 and 212 women with Type 2 diabetes who intended exclusive or partial BF.

\section{Subjects and methods}

This retrospective cohort investigation was approved by the Institutional Review Board at The Ohio State University Wexner Medical Center. Electronic maternal and neonatal records (2013-18) were reviewed. Type 1 and Type 2 pregestational diabetes, chronic hypertension $(\mathrm{CHTN})$ and preeclampsia were diagnosed and treated in accordance with established guidelines $[1,12]$. Women were categorized by prepregnancy BMI as normal $\left(18-24.9 \mathrm{~kg} / \mathrm{m}^{2}\right)$, overweight $\left(25-29.9 \mathrm{~kg} / \mathrm{m}^{2}\right)$, obese $\left(30-39.9 \mathrm{~kg} / \mathrm{m}^{2}\right)$, morbidly obese $\left(40-49.9 \mathrm{~kg} / \mathrm{m}^{2}\right)$ or extremely obese $\left(\geq 50 \mathrm{~kg} / \mathrm{m}^{2}\right)$ [13].

All women delivered singleton infants at $\geq 34$ weeks gestation and those affected by major fetal malformations were not included. Upon arrival to labor and delivery, each woman described her past BF experience and her intention to BF. In our institution, maternity practices include BF within $1 \mathrm{~h}$, no formula supplementation unless indicated, rooming in, on demand $\mathrm{BF}$, full-time lactation consultants and post discharge BF support [14-16]. Furthermore, our institution reports BF data to the Joint Commission as required for hospital accreditation [15].

Per our hospital practice, symptomatic infants were directly transferred from the delivery room to the NICU for further care. Following delivery if the condition of the mother and her infant allowed, maternal-infant interactions such as holding, skin-to-skin contact, and BF were encouraged. Asymptomatic infants able to feed were transferred to the newborn nursery for routine care and glucose monitoring [17].

Screening for hypoglycemia (blood glucose $<40 \mathrm{mg} / \mathrm{dl}$ ) was done via serial point of care testing $\left(\mathrm{Accu}-\mathrm{Chek}^{\circledR}\right)$ or by plasma glucose measurement in the laboratory (Beckman Coulter AU5800, Beckman Coulter Inc., Brea, CA, USA) starting within the first hour of life after the first feeding and every $2-4 \mathrm{~h}$ thereafter as needed. Asymptomatic infants in the newborn nursery with hypoglycemia were promptly $\mathrm{BF}$ or formula fed (FF) and those with recurrent hypoglycemia were transferred to the NICU for further care. On admission to the NICU, most infants were started on intravenous (IV) dextrose while those who were able to feed were BF or FF [17].

$\mathrm{BF}$ was considered early if given within the first two postpartum hours. Exclusive BF was defined as direct feedings from the breast, expressed breast milk (EBM) alone or in combination with direct BF or with donor human milk while hospitalized. Partial BF was defined as formula supplementation with direct BF or with EBM. $\mathrm{BF}$ was considered initiated if, during the $24 \mathrm{~h}$ preceding hospital discharge, infants were BF exclusively or BF partially [17]. Due to the retrospective study design, no follow-up information was available on infant feeding practices after hospital discharge.

\section{Statistical analysis}

Comparisons between women with Type 1 and Type 2 pregestational diabetes were made with Mood's median tests for continuous variables and Chi square tests for categorical variables. Significance was established at a $p$ value $<0.05$. To assess the normality of quantitative variables, we examined quantile-quantile ('Q-Q') plots for visible deviations from model assumptions. No such issues were seen. Univariate and multivariate stepwise logistic regression were used to ascertain the strength of association of Type 1 and Type 2 diabetes with exclusive $\mathrm{BF}$ and $\mathrm{BF}$ initiation at discharge controlling for maternal variables (CHTN, preeclampsia, mothers age, race, BMI, elevated hemoglobin A1c (HbA1c) levels ( $\geq 7.0 \%$ ), multiparity, mode of delivery, prior $\mathrm{BF}$, intention to $\mathrm{BF}$ exclusively, breastfed $<2 \mathrm{~h}$ from birth) and neonatal variables (gestational age, preterm, admission to NICU, neonatal hypoglycemia and infant length of stay). To test for collinearity between independent variables, we removed each one at a time from the full adjusted models presented and confirmed that the remaining estimates did not change drastically, which was always the case.

\section{Results}

The study population consisted of 185 women with Type 1 and 212 women with Type 2 pregestational diabetes who intended to BF.

\section{Comparison of women with type 1 and type 2 diabetes}

Clinical and demographic characteristics of women with Type 1 and Type 2 diabetes are shown in Table 1 . The prevalence of CHTN alone (10 vs $18 \%$ ) and preeclampsia superimposed on CHTN (8 vs $8 \%$ ) were similar for Type 1 and Type 2 women. Preeclampsia as a single comorbidity was more common among Type 1 than Type 2 women (21 vs 7\%, $p$ 0.0001). Preeclampsia alone or superimposed on CHTN combined affected 53 (29\%) of Type 1 and 30 (14\%) of Type 2 women. All women with 
Table 1 Comparison of women with Type 1 and Type 2 Diabetes

\begin{tabular}{|c|c|c|c|}
\hline & Type 1 & Type 2 & $p$ \\
\hline Mother-Infant dyads no. & 185 & 212 & \\
\hline Pregestational DM without comorbidities no. (\%) & $114(62)$ & $144(68)$ & NS \\
\hline Chronic hypertension no. (\%) & $18(10)$ & $38(18)$ & NS \\
\hline Preeclampsia superimposed on CHTN no. (\%) & $15(8)$ & $16(8)$ & NS \\
\hline Preeclampsia no. (\%) & $38(21)$ & $14(7)$ & 0.0001 \\
\hline Mother's age (y) median (IQR) & $30(26,34)$ & $33(29,36)$ & $<0.0001$ \\
\hline \multicolumn{4}{|l|}{ Race } \\
\hline African American no. (\%) & $40(22)$ & $52(25)$ & NS \\
\hline White no. (\%) & $133(72)$ & $73(34)$ & 0.0001 \\
\hline Hispanic no. (\%) & $7(4)$ & $55(26)$ & 0.0001 \\
\hline Other no. (\%) & $5(3)$ & $32(15)$ & 0.0001 \\
\hline Smoking during pregnancy no. (\%) & $10(5)$ & $16(8)$ & NS \\
\hline Former smokers no. (\%) & $22(12)$ & $34(16)$ & NS \\
\hline BMI kg/m² median (IQR) & $32(28,37)$ & $36(31,42.5)$ & $<0.0001$ \\
\hline Normal/overweight-BMl kg/m² $\leq 29$ no. (\%) & $64(35)$ & $28(13)$ & 0.0001 \\
\hline Obese-BMI kg/m² 30-39 no. (\%) & $87(47)$ & $100(47)$ & NS \\
\hline Morbidly/extremely obese-BMI $\geq 40$ no. (\%) & $34(18)$ & $84(40)$ & 0.0001 \\
\hline Multiparous no. (\%) & $98(53)$ & $159(75)$ & 0.0001 \\
\hline \multicolumn{4}{|l|}{ Mode of Delivery } \\
\hline Vaginal no. (\%) & $67(36)$ & $85(40)$ & NS \\
\hline Primary cesarean no. (\%) & $68(37)$ & $56(26)$ & 0.03 \\
\hline Repeat cesarean no. (\%) & $50(27)$ & $71(34)$ & NS \\
\hline Mother length of stay $(\mathrm{d})$ median (IQR) & $4(3,5)$ & $4(3,4)$ & 0.002 \\
\hline
\end{tabular}

preeclampsia with severe features received magnesium sulfate neuroprophylaxis for $24 \mathrm{~h}$.

Women with Type 2 diabetes tend to be older, multiparous, less often white, more often Hispanic and of other ethnicities. Median pregestational BMI was higher among African Americans $\left(36.2 \mathrm{~kg} / \mathrm{m}^{2}\right)$ and Hispanics $\left(35.0 \mathrm{~kg} / \mathrm{m}^{2}\right)$ than among whites $(34.0 \mathrm{~kg} /$ $\left.\mathrm{m}^{2}\right)$ and women in the miscellaneous group $(30.9 \mathrm{~kg} /$ $\left.\mathrm{m}^{2}\right)$. Normal/overweight $\left(\mathrm{BMI} \leq 29 \mathrm{~kg} / \mathrm{m}^{2}\right)$ women were more common in Type 1 (35 vs $13 \%$ ), obese women (BMI $30-39.9 \mathrm{~kg} / \mathrm{m}^{2}$ ) were equally represented $(47$ vs $47 \%)$ and morbidly/extremely obese $\left(\geq 40 \mathrm{~kg} / \mathrm{m}^{2}\right)$ women were more common in Type 2 (40 vs 18\%). Single $\mathrm{HbA1c}$ determinations were recorded from all 185 Type 1 and from $98 \%$ of 212 Type 2 women. HbA1c tests were done after 20 weeks of gestation in $99 \%$ of the Type 1 and in 99\% of the Type 2 women. Gestational age at the time of testing was a median 31 weeks (8-39w) for Type 1 and 32 weeks (15-39w) for Type 2 women. Elevated HbA1c ( $\geq 7.0 \%)$ was found in 43 of 185 Type 1 (23\%) and in 39 of 207 (19\%) of Type 2. Regression analysis showed that after adjusting for confounders, elevated HbA1c $(\geq 7.0 \%)$ was not an independent predictor of exclusive BF or BF initiation for either Type 1 or Type 2 diabetic women.

\section{Neonatal outcomes of infants born to women with type 1 and type 2 diabetes}

Infants born to Type 1 women were of lower median gestational age (37 vs $38 \mathrm{w}$ ) and of higher median birthweight (3618 vs $3390 \mathrm{~g}$ ) (Table 2). Both groups were similar in small for GA (3 vs $2 \%$ ), large for GA (41 vs $37 \%$ ) and appropriate for GA (57 vs 60\%) infants. Of note, macrosomia (birthweight $\geq 4000 \mathrm{~g}$ ) affected 23 and $22 \%$ of infants in Type 1 and Type 2 groups, respectively.

Neonatal hypoglycemia and admission to the NICU occurred more often among infants in the Type 1 group than in the Type 2 group. Considering the similarities in diagnoses, 82 infants from the Type 1 group and 38 infants from the Type 2 group admitted to the NICU were combined for analysis. Seventy-five of the 120 (63\%) infants were admitted to the NICU directly from the delivery room while the remaining $45(37 \%)$ stayed in the newborn nursery for a short time prior to transfer. Primary admission diagnoses to the NICU included hypoglycemia (62\%), respiratory distress (33\%) and 
Table 2 Neonatal outcomes of infants born to women with Type 1 and Type 2 Diabetes

\begin{tabular}{|c|c|c|c|}
\hline & Type 1 & Type 2 & $p$ \\
\hline Mother-Infant dyads no. & 185 & 212 & \\
\hline Males no. (\%) & $94(51)$ & $114(54)$ & NS \\
\hline Birthweight (g) median (IQR) & $3618(3172,3959)$ & $3390(3107,3922)$ & 0.002 \\
\hline Gestational age (W) median (IQR) & $37(37,38)$ & $38(37,39)$ & 0.02 \\
\hline Preterm no. (\%) & $40(22)$ & $34(16)$ & NS \\
\hline \multicolumn{4}{|l|}{ Intrauterine Growth } \\
\hline Small for gestational age no. (\%) & $5(3)$ & $5(2)$ & NS \\
\hline Large for gestational age no. (\%) & $75(41)$ & $79(37)$ & NS \\
\hline Macrosomia no. (\%) & $43(23)$ & $47(22)$ & NS \\
\hline Admission to NICU no. (\%) & $82(44)$ & $38(18)$ & 0.0001 \\
\hline aNeonatal hypoglycemia no. (\%) & $109(59)$ & $86(41)$ & 0.0003 \\
\hline Infant length of stay (d) median (IQR) & $3(3,4)$ & $3(2.5,3.5)$ & 0.08 \\
\hline Discharged home with mother no. (\%) & $173(94)$ & $200(94)$ & NS \\
\hline
\end{tabular}

a Includes infants cared for in the Newborn Nursery or the NICU

apnea-bradycardia-cyanosis (5\%). Additionally, temperature instability-hypotonia-poor feeding affected onethird of all infants. Twenty-two of the 120 infants (18\%) stayed in the NICU for less than 1 day, 23 infants (19\%) stayed 2 days and the remaining 75 (63\%) stayed 3 days or longer. All mothers and their infants were discharged home in good condition.

\section{Prior BF experience and early BF among women with type 1 and type 2 diabetes}

The prevalence of multiparous women was lower in the Type 1 than in the Type 2 group (53 vs 75\%), however, relevant to our study, prior BF experience among the multiparous women in either group was similar (69 vs 67\%) (Table 3).

Table 3 Prior BF experience and early BF among women with Type 1 and Type 2 Diabetes

\begin{tabular}{llll}
\hline & Type 1 & Type 2 & $\boldsymbol{p}$ \\
\hline Mother-Infant dyads no. & 185 & 212 & \\
Multiparous no. (\%) & $98(53)$ & $159(75)$ & 0.0001 \\
$\quad$ Prior breastfeeding no. (\%) & $68(69)$ & $107(67)$ & NS \\
Intended partial BF no. (\%) & $14(8)$ & $47(22)$ & 0.0001 \\
Intended exclusive BF no. (\%) & $171(92)$ & $165(78)$ & 0.0001 \\
Time to First Breastfeeding & & & \\
$\quad<1$ h no. (\%) & $74(40)$ & $87(41)$ & NS \\
1-2h no. (\%) & $8(4)$ & $19(9)$ & NS \\
3-4h no. (\%) & $19(10)$ & $15(7)$ & NS \\
5-6h no. (\%) & $11(6)$ & $10(5)$ & NS \\
7-24h no. (\%) & $32(17)$ & $32(15)$ & NS \\
$\geq 25$ h no. (\%) & $20(11)$ & $18(8)$ & NS \\
$\quad$ Never breastfed no. (\%) & $21(12)$ & $31(15)$ & NS \\
Received lactation consult no. (\%) & $174(94)$ & $201(95)$ & NS \\
\hline
\end{tabular}

Eighty-two of the 185 Type 1 (44\%) and 106 of 212 (50\%) of Type 2 infants BF during the first $2 \mathrm{~h}$ from birth.

Analysis of mode of delivery on early BF showed that of 67 women from the Type 1 group who delivered vaginally, 41 (61\%) were able to BF within $2 \mathrm{~h}$ from birth, similar to those 57 of 85 (67\%) in the Type 2 group. Among 118 women from the Type 1 group who delivered by cesarean, 39 (33\%) were able to BF within $2 \mathrm{~h}$ from birth, similar to 49 of 127 (39\%) of those in the Type 2 group.

BF at discharge for women with type 1 and type 2 diabetes At discharge, exclusive BF was 34\% among Type 1 women and $23 \%$ for those in the Type 2 group (Table 4 ). In the Type 1 group were 171 women who intended exclusive BF, of them 61 (36\%) BF exclusively at discharge. Conversely, of 14 others who intended partial BF only one (7\%) BF exclusively at discharge. In the Type 2 group

Table 4 BF at discharge for women with Type 1 and Type 2 Diabetes

\begin{tabular}{llll}
\hline & Type 1 & Type 2 & $\boldsymbol{p}$ \\
\hline Mother-Infant dyads no. & 185 & 212 & \\
Multiparous no. (\%) & $98(53)$ & $159(75)$ & 0.0001 \\
$\quad$ Prior Breastfeeding no. (\%) & $68(69)$ & $107(67)$ & NS \\
Infant Feeding at Discharge & & & \\
Exclusive total no. (\%) & $62(34)$ & $49(23)$ & 0.02 \\
$\quad$ Direct BF no. (\%) & $40(65)$ & $46(94)$ & 0.0001 \\
$\quad$ Expressed breast milk/Donor no. (\%) & $22(35)$ & $3(6)$ & 0.0001 \\
Partial total no. (\%) & $87(47)$ & $98(46)$ & NS \\
$\quad$ Direct BF \& Formula no. (\%) & $77(89)$ & $94(96)$ & NS \\
$\quad$ Expressed breast milk \& Formula no. (\%) & $10(11)$ & $4(4)$ & NS \\
Formula feeding no. (\%) & $36(19)$ & $65(31)$ & 0.01 \\
Breastfeeding initiation no. (\%) & $149(81)$ & $147(69)$ & 0.01 \\
\hline
\end{tabular}


were 165 women who intended exclusive BF, of them 47 (28\%) BF exclusively at discharge. In contrast, of 47 others who intended partial BF only $2(4 \%)$ BF exclusively at discharge. Regression analysis showed that the stronger predictor of failure to exclusive BF at discharge for Type 1 women was neonatal hypoglycemia a OR 0.34 CI 95\% $(0.17,0.68)$ and for Type 2 women were intention to partially BF a OR 0.10 CI $95 \%(0.02,0.44)$ and neonatal hypoglycemia a OR 0.35 CI $95 \%(0.15,0.79)$.

Of the 62 Type 1 infants in the exclusive BF subgroup, 40 received direct BF, 16 exclusive EBM and 6 exclusive donor human milk. Of the 49 infants in the Type 2 exclusive BF subgroup, 46 received direct BF, 2 exclusive EBM and 1 exclusive donor human milk. Partial BF rates were similar (47 vs 46\%), formula feeding was lower (19 vs $31 \%$ ) and $\mathrm{BF}$ initiation at discharge was higher (81 vs 69\%) among Type 1 compared to Type 2 women. Regression analysis showed that the stronger predictors of $\mathrm{BF}$ initiation for Type 1 were BMI a OR 0.92 CI 95\% (0.87, $0.99)$ and mothers age (a OR 1.07 CI $95 \%(0.99,1.15)$. For infants in the Type 2 group the stronger predictors of $\mathrm{BF}$ initiation failure were intention to partially BF a OR 0.22 CI $95 \%(0.10,0.50)$ and neonatal hypoglycemia a OR 0.35 CI 95\% (0.15, 0.79).

Regardless of mode of delivery, 82 women from the Type 1 group (44\%) and 106 women from the Type 2 group (50\%) BF during the first $2 \mathrm{~h}$. At discharge, 76 of 82 (93\%) Type 1 and 91 of 106 (86\%) Type 2, respectively, initiated BF. On the other hand, 73 of 103 (71\%) women from the Type 1 and 49 of 106 (46\%) women from the Type 2 group who did not BF within $2 \mathrm{~h}$ initiated $\mathrm{BF}$ at discharge.

A comparison of Type 1 and Type 2 women combined according to race, showed that BF initiation at discharge was observed in $85 \%$ of 206 whites, in $66 \%$ of 92 African Americans, in $64 \%$ of 62 Hispanics and in $81 \%$ of 37 women from the other group. Concurrently, the rate of exclusive BF was $29 \%$ for whites, $27 \%$ for the miscellaneous groups, 20\% for African Americans and 19\% for Hispanics. Logistic regression analysis showed that exclusive BF among Type 1 women was less likely among nonwhite women a OR 0.44 CI 95\% $(0.19,1.00)$.

\section{Prior BF experience, exclusive BF and BF initiation in women with type 1 and type 2 diabetes}

Inspite of the different prevalence of multiparous women, prior BF experience was similar among Type 1 and Type 2 groups. Further analysis showed that 68 Type 1 women with prior BF experience had higher exclusive BF (41 vs $29 \%$ ) and $\mathrm{BF}$ initiation rates (88 vs $76 \%$ ) than 117 others without prior BF experience. Among Type 2 women, 107 with prior experience had higher exclusive BF (27 vs $19 \%$ ) and BF initiation rates (78 vs 61\%) than 105 without prior BF experience. Logistic regression showed that prior BF was a strong predictor of exclusive BF among Type 1 a OR 4.07 CI 95\% $(1.21,13.65)$ and among Type 2 a OR 3.96 CI 95\% (1.82, 8.62). Similar analysis showed that prior $\mathrm{BF}$ was also a strong predictor of $\mathrm{BF}$ initiation among Type 1 a OR 4.12 CI 95\% $(1.10,15.47)$ and among Type 2 women a OR 4.17 CI 95\% $(1.88,9.28)$.

\section{Maternal obesity, type of diabetes and BF initiation}

Sixty-four of 185 (35\%) Type 1 and 28 of 212 (13\%) Type 2 women were normal or overweight (BMI $\left.<29 \mathrm{~kg} / \mathrm{m}^{2}\right)$. At discharge, exclusive BF (39 vs $36 \%$ ) and BF initiation (87 vs 79\%) were similar for both groups. Eighty-seven of 185 Type 1 (47\%) and 100 of 212 (47\%) of Type 2 women were obese (BMI $30-39.9 \mathrm{~kg} / \mathrm{m}^{2}$ ). At discharge exclusive BF was higher (35 vs $22 \%, p 0.05$ ) in the Type 1 group but BF initiation ( 80 vs $78 \%$ ) was similar for both groups. Thirtyfour of 185 (18\%) Type 1 women and 84 of $212(40 \%)$ Type 2 were morbidly/extremely obese $\left(\mathrm{BMI} \geq 40 \mathrm{~kg} / \mathrm{m}^{2}\right)$. At discharge, exclusive BF (21 vs $20 \%$ ) and BF initiation (71 vs $68 \%$ ) were similar for both groups.

\section{Discussion}

The American Academy of Pediatrics and the Academy of Breastfeeding Medicine recommend exclusive BF for all healthy infants during birth hospitalization and beyond [16, 18]. Since January 2014, the joint commission mandated exclusive BF during hospitalization for healthy infants to retain their maternity accreditation [15]. These organizations acknowledged that other nutritional options may be needed to temporarily replace or supplement BF under well-defined circumstances (i.e., maternal and neonatal illness, late preterm infants) [15, 18]. In a recent study of maternity care practices and policies in 1305 hospitals in the United States, the mean percentage of in-hospital exclusive BF infants in the general population was $51.4 \%$ [19]. Recently, we reported exclusive BF rates in women with mild (47\%) and severe CHTN (50\%) [20], with preeclampsia (39\%) and with severe preeclampsia (37\%) [21], with preeclampsia superimposed on pregestational diabetes (18\%) [22], with CHTN superimposed on pregestational diabetes (19\%) [23], with pregestational diabetes with (33\%) and without prior BF experience (11\%) [24]. The low exclusive BF rates for Type 1 (34\%) and Type 2 (23\%) women reported here are similar to those of women with pregestational diabetes with superimposed comorbidities described above [22-24].

In the US $83.2 \%$ of newborns initiated BF by the time of discharge from the birth hospital [25]. In the present study we observed a BF initiation rate of $81 \%$ for Type 1 and $69 \%$ for Type 2 women. Obstacles known to associate with low BF initiation affecting our study 
population included lack of prior BF experience, preeclampsia, CHTN, pregestational diabetes, obesity, complications of labor, cesarean delivery, premature birth, neonatal hypoglycemia, admission to NICU, late or absent BF, formula supplementation, delayed lactogenesis II and maternal infant separation [21, 26, 27]. Our regression analysis showed that the strong predictors of $\mathrm{BF}$ initiation for Type 1 were lower BMIs and younger maternal age, whereas among Type 2 predictors of $\mathrm{BF}$ initiation failure were intention to partially $\mathrm{BF}$, higher BMI and neonatal hypoglycemia.

It is known that racial discrepancies in prevalence are accompanied by low rates of BF initiation and exclusive BF in African American and Hispanics as compared to non-Hispanic whites $[28,29]$. In line with the above, our data on Type 1 and Type 2 combined also showed that exclusive BF and BF initiation among African American was lower than those of non-Hispanic white women.

Hypoglycemia, lack of early BF and admission to NICU are well known interrelated obstacles to exclusive BF and BF initiation among infants born to women with gestational and pregestational diabetes [17-26]. Timing of the first BF is important because many critical maternal and neonatal physiological interactions occur following delivery $[17,26,30]$. Persistent hypoglycemia is commonly found among infants born to women with Type 1 and Type 2 diabetes during the first hours after birth [17, 31]. Early BF or early FF may facilitate glycemic stability in infants born to women with pregestational diabetes and may prevent or correct hypoglycemia avoiding the need for dextrose gel, IV treatment or formula supplementation $[17,31]$.

Comorbidities like preeclampsia, CHTN, obesity, cesarean delivery, preterm birth, hypoglycemia, NICU admission and early BF may have all contributed to the low BF initiation observed in this investigation [20-23, $31,32]$. The high rate of cesarean deliveries in the Type 1 and Type 2 groups is not unexpected, especially for women with high-risk obstetrical conditions superimposed on obesity [27, 32, 33]. Women from either group who BF exclusively by EBM without any direct BF is also of concern because pumping without feeding at the breast is associated with shorter BF duration [34].

Prior BF experience is a predictor, albeit not absolute, of subsequent BF. In contrast, women who did not BF or who reported unsuccessful attempts to BF their first child are unlikely to BF subsequent children $[35,36]$. At discharge, exclusive $\mathrm{BF}$ and $\mathrm{BF}$ initiation rates were higher for women with prior experience than for those without [24]. In the current study, Type 1 and Type 2 women with prior $\mathrm{BF}$ experience had better rates of exclusive $\mathrm{BF}$ and $\mathrm{BF}$ initiation than those without experience.
A positive BF experience improves attitude, confidence, self-efficacy, motivation and intention to BF [24, 35-37]. Negative BF experiences are related to maternal or neonatal morbidities or to difficulties inherent to lactation such as suck/latch problems, perception of low milk supply, mastitis or nipple fissures [24, 37]. Multiparous women who declare no prior BF experience represent a group that attempted to $\mathrm{BF}$ and were unsuccessful or who did not intend to BF [24, 35, 36]. A detailed BF history could provide insight into obstacles and may help to define appropriate preventive or corrective strategies for subsequent pregnancies [24].

The association of obesity, type of diabetes and BF initiation reported here is not surprising since obesity, especially if linked with delayed lactogenesis II, has a negative effect on rates of exclusive $\mathrm{BF}, \mathrm{BF}$ initiation and BF duration [33]. Women who are obese are more likely to have comorbidities including preeclampsia, CHTN and preexisting diabetes and are at increased risk for cesarean delivery and fetal macrosomia, all factors known to negatively influence BF outcomes [20, $21,33]$. The lack of association of elevated HbA1c with exclusive $\mathrm{BF}$ or $\mathrm{BF}$ initiation in this study population was not unexpected because $\mathrm{HbA1c}$ level alone does not take into account glycemic variability especially during the third trimester $[38,39]$.

The major limitation of this investigation is that the definition of exclusive $\mathrm{BF}$ and $\mathrm{BF}$ initiation at discharge used here may be applicable only to women with high risk obstetrical conditions for whom early motherinfant interactions may be delayed [27]. Another limitation is the lack of follow-up information regarding infant feeding choices after discharge from the hospital. The strength of this investigation rests on the size of the obstetrical and neonatal population and the fact that the data were obtained directly from medical records and not from maternal recall or via post-delivery questionnaires [40].

In conclusion, intention to BF exclusively was higher in Type 1 women compared to Type 2. Exclusive BF in women with either Type 1 or Type 2 diabetes fell short of expectations, raising concerns about long term $\mathrm{BF}$ duration. Women and infants who are not ready for direct $\mathrm{BF}$ can be helped by temporary alternatives such as EBM or donor human milk. At discharge, exclusive $\mathrm{BF}$ and $\mathrm{BF}$ initiation were lower and $\mathrm{FF}$ higher in the Type 2 group, highlighting the need for different strategies if lactation in these special populations is to be improved.

\section{Acknowledgements}

Statistical support was provided by the Ohio Perinatal Research Network (OPRN). 


\section{Authors' contributions}

All authors participated in planning and research design. Data analysis and manuscript preparation - LC. Manuscript revisions - LC, CAN, MRS and MBL. The author(s) read and approved the final manuscript.

\section{Funding}

The author(s) received no financial support for the research, authorship, and/ or publication of this article.

\section{Availability of data and materials}

The data sets generated during and analyzed during the current study are not publicly available due to limitations of ethical approval involving the patient data and anonymity but are available from the corresponding author on reasonable request.

\section{Declarations}

Ethics approval and consent to participate

The Ohio State University Biomedical Science IRB approved on 5/11/2021 the study \#2010H0198 with waivers of informed consent and HIPAA research authorization. All methods were performed in accordance with the relevant guidelines and regulations of the declaration of Helsinki.

\section{Consent for publication}

Not applicable.

\section{Competing interests}

The Author(s) declare(s) that there is no conflict of interest.

\section{Author details}

${ }^{1}$ Department of Pediatrics, College of Medicine, The Ohio State University Wexner Medical Center, N1 18 Doan Hall, 410 W. 10th Avenue, Columbus, OH 43210-1228, USA. ${ }^{2}$ Department of Obstetrics, College of Medicine, The Ohio State University Wexner Medical Center, N118 Doan Hall, 410 W. 10th Avenue, Columbus, $\mathrm{OH}$ 43210-1228, USA.

Received: 5 August 2021 Accepted: 17 January 2022

Published online: 27 January 2022

\section{References}

1. Practice ACOG. Bulletin \#201. Pregestational diabetes mellitus. Obstet Gynecol. 2018;132:e228.

2. Admon LK, Winkelman TNA, Moniz MH, Davis MM, Heisler M, Dalton VK. Disparities in chronic conditions among women hospitalized for delivery in the United States, 2005-2014. Obstet Gynecol. 2017;130:1319-26.

3. Peng TY, Ehrlich SF, Crites Y, Kitzmiller JL, Kuzniewicz MW, Hedderson MM, et al. Trends and racial and ethnic disparities in the prevalence of pregestational type 1 and type 2 diabetes in northern California: 1996-2014. Am J Obstet Gynecol. 2017;216:177.e1-8. https://doi.org/10.1016/j.ajog.2016. 10.007 .

4. Simmons D, Conroy C, Thompson CF. In-hospital breast feeding rates among women with gestational diabetes and pregestational type 2 diabetes in South Auckland. Diabet Med. 2005;22:177-81.

5. Soltani $\mathrm{H}$, Arden M. Factors associated with breastfeeding up to 6 months postpartum in mothers with diabetes. J Obstet Gynecol Neonatal Nurs. 2009;38:586-94. https://doi.org/10.1111/j.1552-6909.2009.01052.x.

6. Sorkio S, Cuthbertson D, Bärlund S, Reunanen A, Nucci AM, Berseth CL, et al. Breastfeeding patterns of mothers with type 1 diabetes: results from an infant feeding trial. Diabetes Metab Res Rev. 2010;26:206-11. https:// doi.org/10.1002/dmrr.1074

7. Herskin CW, Stage E, Barfred C, Emmersen P, Nichum VL, Damm P, et al. Low prevalence of long-term breastfeeding among women with type 2 diabetes. J Matern Fetal Neonatal Med. 2016;29:2513-8.

8. Gunderson EP, Hurston SR, Ning X, Lo JC, Crites Y, Walton D, et al. Lactation and progression to type 2 diabetes mellitus: a prospective cohort study. Ann Intern Med. 2015;163:889-98.
9. Stuebe A. Associations among lactation, maternal carbohydrate metabolism and cardiovascular health. Clin Obstet Gynecol. 2015;58:827-39. https://doi.org/10.1097/GRF.0000000000000155.

10. Binns C, Lee M, Low WY. The long-term public health benefits of breastfeeding. Asia Pac J Public Health. 2016;28:7-14.

11. Nguyen B, Jin K, Ding D. Breastfeeding and maternal cardiovascular risk factors and outcomes: a systematic review. Plos One. 2017;12(11):e0187923 https://doi.org/10.1371/journal.pone.0187923.

12. Practice ACOG. Bulletin \#203. Chronic hypertension in pregnancy. Obstet Gynecol. 2019;133:e26.

13. World Health Organization. Body mass index. http://www.euro.who.int/ en/health-topics/disease-prevention/nutrition/a-healthy-lifestyle/bodymass-index-bmi.Accessed October 25, 201.

14. Nelson JM, Perrine CG, Freedman DS, Williams L, Morrow B, Smith RA, et al. Infant feeding-related maternity care practices and maternal report of breastfeeding outcomes. Birth. 2018;45:424-31. https://doi.org/10. 1111/birt.12337.

15. JCAHO Specifications manual for national quality measures (v2015B). From https://manual.jointcommission.org. Accessed 1/19/2021

16. Patterson JA, Keuler NS, Olson BH. The effect of baby-friendly status on exclusive breastfeeding in U.S. hospitals. Matern Child Nutr. 2018;14:e12589. https://doi.org/10.1111/mcn.12589.

17. Cordero L, Stenger MR, Landon MB, Nankervis CA. Early feeding, hypoglycemia, and breastfeeding initiation in infants born to women with pregestational diabetes mellitus. J Neonatal Perinatal Med. 2018;11:35764. https://doi.org/10.3233/NPM-17145.

18. Boies EG, Vaucher YE. ABM clinical protocol \#10: breastfeeding the late preterm (34-36 6/7 weeks of gestation) and early term infants (37-38 6/7 weeks of gestation), second revision 2016. Breastfeed Med. 2016;11:494-500

19. Barrera CM, Beauregard JL, Nelson JM, Perrine CG. Association of maternity care practices and policies with in-hospital exclusive breastfeeding in the United States. Breastfeed Med. 2019;14(4):243-8. https://doi.org/10. 1089/bfm.2018.0196.

20. Cordero L, Stenger MR, Landon MB, Nankervis CA. Breastfeeding initiation among women with chronic hypertension. Int J Womens Health Wellness. 2021;7:118. https://doi.org/10.2337/2474-1353/1510118.

21. Cordero L, Stenger MR, Landon MB, Nankervis CA. Breastfeeding initiation among women with preeclampsia with and without severe features. J Neonatal Perinatal Med. 2020. https://doi.org/10.3233/npm-200508 Online ahead of print.

22. Cordero L, Stenger MR, Landon MB, Nankervis CA. Breastfeeding initiation among women with preeclampsia with severe features superimposed on diabetes mellitus. Int J Women's Health Wellness. 2021;6:115. https://doi. org/10.23937/2474-1353/1510115.

23. Cordero L, Stenger MR, Landon MB, Nankervis CA. Breastfeeding initiation among women with chronic hypertension superimposed on pregestational diabetes mellitus. J Neonatal Perinatal Med. 2021;Online ahead of print. https://doi.org/10.3233/NPM-210738.

24. Cordero L, Stenger MR, Blaney SD, Finneran MM, Nankervis CA. Prior breastfeeding experience and infant feeding at discharge among women with pregestational diabetes mellitus. J Neonatal Perinatal Med. 2020:13.563-70 https//doi.org/10.3233/NPM-190308.

25. Centers for Disease Control and Prevention. Breastfeeding report card 2018. From https://www.cdc.gov/breastfeeding/pdf/2018breastfeedi ngreportcard.pdf. Accessed 1/19/2021

26. Cordero L, Thung S, Landon MB, Nankervis CA. Breastfeeding initiation failure in women with pregestational diabetes mellitus. Clin Pediatr. 2014;53:18-25.

27. Cordero L, Oza-Frank R, Moore-Clingenpeel M, Landon MB, Nankervis CA. Failure to initiate breastfeeding among high risk obstetrical patients who intended to breastfeed. J Neonatal Perinatal Med. 2016:9:401-9.

28. Louis-Jacques A, Deubel TF, Taylor M, Stuebe AM. Racial and ethnic disparities in U.S. breastfeeding and implications for maternal and child health outcomes. Semin Perinatol. 2017;41:299-307.

29. Beauregard JL, Hamner HC, Chen J, Avila-Rodriguez W, Elam-Evans LD, Perrine CG. Racial disparities in breastfeeding initiation and duration among U.S. infants born in 2015. MMWR Morb Mortal Wkly Rep. 2019;68:745-8

30. Robiquet P, Zamiara PE, Rakza T, Deruelle P, Mestdagh B, Blondel G, et al. Observation of skin-to-skin contact and analysis of factors linked 
to failure to breastfeed within 2 hours after birth. Breastfeed Med. 2016;11:126-32

31. Harding JE, Harris DL, Hegarty JE, Alsweiler JM, McKinlay CJD. An emerging evidence base for the management of neonatal hypoglycemia. Early Hum Dev. 2017;104:51-6.

32. Hobbs AJ, Mannion CA, McDonald SW, Brockway M, Tough SC. The impact of caesarean section on breastfeeding initiation, duration and difficulties in the first four months postpartum. BMC Pregnancy Childbirth. 2016;16:90.

33. Ramji N, Challa S, Murphy PA, Quinlan J, Crane JMG. A comparison of breastfeeding rates by obesity class. J Matern Fetal Neonatal Med. 2018;31:3021-6.

34. Keim SA, Boone KM, Oza-Frank R, Geraghty SR. Pumping milk without ever feeding at the breast in the Moms2Moms study. Breastfeed Med. 2017;12:422-9.

35. Bai DL, Fong DYT, Lok KYW, Wong JYH, Tarrant M. Prior breastfeeding experience and duration of any and exclusive breastfeeding among multiparous mothers. Birth. 2015;42:70-7.

36. Huang $Y$, Ouyang YQ, Redding SR. Previous breastfeeding experience and its influence on breastfeeding outcomes in subsequent births: a systematic review. Women Birth. 2019;32:303-9.

37. Colombo L, Crippa BL, Consonni D, Bettinelli ME, Agosti V, Mangino G, et al. Breastfeeding determinants in healthy term newborns. Nutrients. 2018;10:48. https://doi.org/10.3390/nu10010048.

38. Edelson PK, James KE, Leong A, Arenas J, Cayford M, Callahan MJ, et al. Longitudinal changes in the relationship between hemoglobin A1c and glucose tolerance aross pregnancy and postpartum. J Clin Endocrinol Metab. 2020;105:e1999-2007.

39. Jotic A, Milicic T, Lalic K, Lukic L, Macesic M, Stanarcic Gajovic J, et al. Evaluation of glycaemic control, glucose variability and hypoglycaemia on long-term continuous subcutaneous infusion vs. multiple daily injections: observational study in pregnancies with pre-existing type 1 diabetes. Diabetes Ther. 2020;11:845-58. https://doi.org/10.1007/ s13300-020-00780-7.

40. Keenan K, Hipwell A, McAloon R, Hoffmann A, Mohanty A, Magee K. Concordance between maternal recall of birth complications and data from obstetrical records. Early Hum Dev. 2017;105:11-5. https://doi.org/ 10.1016/j.earlhumdev.2017.01.003

\section{Publisher's Note}

Springer Nature remains neutral with regard to jurisdictional claims in published maps and institutional affiliations.

Ready to submit your research? Choose BMC and benefit from:

- fast, convenient online submission

- thorough peer review by experienced researchers in your field

- rapid publication on acceptance

- support for research data, including large and complex data types

- gold Open Access which fosters wider collaboration and increased citations

- maximum visibility for your research: over 100M website views per year

At BMC, research is always in progress.

Learn more biomedcentral.com/submissions 